\title{
Mobilidade urbana para pessoas com deficiência no Brasil: um estudo em blogs
}

\author{
Urban mobility for people with disabilities in Brazil: a study on blogs
}

Adriana Silva Barbosa ${ }^{[0]}$

[a] Universidade Estadual de Campinas (UNICAMP), Campinas, SP, Brasil

\section{Resumo}

A mobilidade urbana considera as condições de deslocamento das pessoas e bens pela cidade. 0 objetivo deste estudo é analisar como os blogs com a temática deficiência retratam a mobilidade urbana para pessoas com deficiência no Brasil. Para tanto, foi realizada uma pesquisa qualitativa e exploratória, na qual foram analisadas postagens de 15 blogs de pessoas com deficiência com o emprego da Grounded Theory. Reconhecer a mobilidade urbana como condição estratégica para a inclusão de pessoas com deficiência foi identificada como categoria central deste estudo, à qual se subordinam dezesseis subcategorias, organizadas em cinco eixos: necessidade de mudanças, sentimentos, efetivação da mudança, investimentos financeiros e consequências. Estes resultados mostram que a mobilidade urbana é considerada pelas pessoas com deficiência como estratégica para sua inclusão social e que os blogs evidenciam suas necessidades, reivindicações, reflexões, discussões e apontam soluções para os problemas que enfrentam em seu cotidiano.

Palavras-chave: Mobilidade urbana. Acessibilidade. Pessoa com deficiência. Deficiência. Inclusão social.

\section{Abstract}

Urban mobility considers people and goods displacement conditions around the city. This study aims to analyze how blogs on disability portray the urban mobility for people with disabilities in Brazil. Therefore, a qualitative and exploratory research was conducted, in which posts of 15 blogs owned by people with disabilities were analyzed using the Grounded Theory. Recognizing urban mobility as a strategic condition for the inclusion of people with disabilities has been identified as the central category of this study, to which are subordinated sixteen subcategories, organized into five axis: the need for changes, feelings, effecting change, financial investments and consequences. These results show that urban mobility is considered by people with disabilities as strategic for their social inclusion and that blogs show their needs, claims, reflections, discussions and suggest solutions to the problems they face in their daily lives.

Keywords: Urban mobility. Accessibility. People with disabilities. Disability. Social inclusion.

ASB é Bióloga, doutoranda em Política Científica e Tecnológica pela Unicamp; Mestre em Enfermagem e Saúde pela Universidade Estadual do Sudoeste da Bahia; Especialista em Metodologia do Ensino Superior pelas Faculdades Integradas de Jequié, e-mail: drybarbosa@yahoo.com.br,drybarbosa@gmail.com 


\section{Introdução}

O objeto de estudo deste artigo é o panorama brasileiro de mobilidade urbana para pessoas com deficiência, expresso em blogs elaborados por pessoas com deficiência neste país.

A mobilidade urbana pode ser entendida como as condições de deslocamento humano e de bens pela cidade, independente da forma de transporte empregada: coletivo ou individual, motorizado ou não (Gomide \& Galindo, 2013). Além disso, envolve também o planejamento urbano associado ao crescimento das cidades, às questões de transporte, sua disponibilidade para a população e o processo de circulação urbana de pessoas; o qual, consequentemente, interfere na demanda de transportes, nas áreas de estacionamento e nos congestionamentos de veículos (Magagnin \& Silva, 2008). Isso significa que a mobilidade urbana está profundamente relacionada à acessibilidade, ao direito e à necessidade que as pessoas têm de se locomover pelas cidades.

As crescentes preocupações sobre o padrão de consumo humano, as quais se relacionam com o padrão de mobilidade, têm levado a questionamentos e ao incremento das pesquisas referentes à relação entre os diferentes padrões de expansão urbana e os custos sociais e ambientais, principalmente no contexto norte-americano e, mais recentemente, na Europa (Camagni et al., 2002). Foi nesta conjuntura que se desenvolveu o conceito de mobilidade urbana sustentável.

A mobilidade urbana é considerada sustentável quando promove o acesso universal das pessoas à cidade e às oportunidades por ela oferecidas, contribuindo para o desenvolvimento socioeconômico, utilizando racionalmente a infraestrutura viária e sem agredir o meio ambiente (Gomide \& Galindo, 2013).

Deve-se ressaltar que, neste processo de implementação da mobilidade urbana sustentável, é imprescindível a participação de todas as pessoas, inclusive daquelas que possuem deficiência; pois, segundo Imrie (2000), a mobilidade e a capacidade de ir e vir são fundamentais para a identidade das pessoas, suas experiências de vida e oportunidades, principalmente para aquelas cuja mobilidade e padrões de movimento são limitados por circunstâncias sociais ou situacionais mais amplas sobre as quais se tem pouco ou nenhum controle. Sob esta perspectiva, Cohen (2006) diz que a mobilidade urbana pode ser encarada como um fenômeno resultante das características corporais das pessoas ou do seu lugar na cidade.

AConvenção dos Direitos das Pessoas com Deficiência da qual o Brasil é signatário define as pessoas com deficiência como "[...] aquelas que têm impedimentos de longo prazo de natureza física, mental, intelectual ou sensorial, os quais, em interação com diversas barreiras, podem obstruir sua participação plena e efetiva na sociedade em igualdades de condições com as demais pessoas [...]" (Brasil, 2011b, p. 26). Disso se depreende que as iniquidades referentes à mobilidade e à capacidade de movimento das pessoas com deficiência encontram-se conectadas a valores socioculturais e práticas que priorizam a mobilidade de corpos socialmente caracterizados sob padrões definidos de saúde, capacidade física e movimentos independentes (Imrie, 2000).

No Brasil, em janeiro de 2012, começou a vigorar a Lei 12.587 que instituiu a Política Nacional de Mobilidade e criou o Sistema Nacional de Mobilidade Urbana, que visa organizar os modos de transporte, a infraestrutura e os serviços que garantam o deslocamento de pessoas e cargas nos territórios dos municípios, demandando que estes elaborem seu Plano Municipal de Mobilidade Urbana (Brasil, 2012). Um aspecto importante desta política é sua fundamentação na acessibilidade e na equidade entre as pessoas, conforme especificam seus princípios, expressos no artigo $5^{\circ}$ da referida lei:

Art. 5o-- A Política Nacional de Mobilidade Urbana está fundamentada nos seguintes princípios: I - acessibilidade universal; II - desenvolvimento sustentável das cidades, nas dimensões socioeconômicas e ambientais; III - equidade no acesso dos cidadãos ao transporte público coletivo; IV - eficiência, eficácia e efetividade na prestação dos serviços de transporte urbano; V - gestão democrática e controle social do planejamento e avaliação da Política Nacional de Mobilidade Urbana; VI - segurança nos deslocamentos das pessoas; VII - justa distribuição dos benefícios e ônus decorrentes do uso dos diferentes modos e serviços; VIII - equidade no uso do espaço público de circulação, vias e logradouros; e IX - eficiência, eficácia e efetividade na circulação urbana (Brasil, 2012, s.p., grifo nosso).

Estes princípios da Lei 12.587/2012 visam promover a mobilidade urbana sustentável nos municípios brasileiros e contemplar as necessidades de todas as 
pessoas, inclusive daquelas que possuem algum tipo de deficiência, conforme especifica o inciso IV de seu artigo 24 (Brasil, 2012); todavia muitas pessoas com deficiência, em várias partes do Brasil, encontram obstáculos que dificultam ou impossibilitam sua mobilidade, restringindo-as ao seu ambiente doméstico e cerceando sua independência, sua capacidade de ter uma vida produtiva e seu direito de ir e vir.

Muitas das críticas às condições de mobilidade urbana no Brasil, inclusive no que concerne à falta de acessibilidade das vias públicas às pessoas com deficiência, são expressas em blogs na internet elaborados por estas pessoas. Os blogs são publicações on line de interesse geral que geralmente abordam aspectos relacionados a uma determinada temática e são voltados para um público específico. Os blogs de pessoas com deficiência costumam abordar os múltiplos aspectos do viver com deficiência, dentre os quais a mobilidade urbana e a acessibilidade.

Assim, decorridos três anos da publicação da Lei 12.587/2012 (Brasil, 2012), torna-se relevante conhecer como os blogs cuja temática é a deficiência têm retratado a mobilidade urbana e a acessibilidade para as pessoas com deficiência. Para tanto, elaboramos a seguinte questão norteadora: como os blogs com a temática deficiência retratam a mobilidade urbana para pessoas com deficiência no Brasil? Para responder a este questionamento, elaboramos o objetivo: analisar como os blogs com a temática deficiência retratam a mobilidade urbana para pessoas com deficiência no Brasil.

\section{Metodologia}

Este artigo caracteriza-se como uma pesquisa qualitativa de cunho descritivo e exploratório. A pesquisa qualitativa ocupa-se do universo de significados, motivos, aspirações, crenças, valores e atitudes que dificilmente pode ser traduzido em números (Minayo, 2007). A pesquisa descritiva busca descrever as características de uma determinada população ou fenômeno, enquanto a pesquisa exploratória destina-se a desenvolver, esclarecer e modificar conceitos e ideias, buscando maior familiaridade com o problema (Gil, 2008).

Esta pesquisa foi realizada em blogs, que possuem a deficiência como temática e que são elaborados por pessoas com deficiência, e teve como intuito retratar como este segmento de blogs retrata a mobilidade urbana para as pessoas com deficiência no Brasil. No estudo foram incluídos 15 blogs com base nas seguintes etapas e critérios de seleção:

1. Foi realizada a pesquisa dos blogs no website de buscas Google com o emprego da combinação das seguintes palavras-chave: blog e deficiente. Foi usado o termo deficiente e não pessoa com deficiência, pois o termo deficiente produziu maior quantidade de resultados. 0 Google forneceu 2.250.000 resultados. Destes, foram verificados os resultados das 20 primeiras páginas (os 200 primeiros resultados). Foram considerados blogs os sites que possuíam em seu endereço eletrônico, em seu nome ou em sua descrição apresentada nos resultados do Google a palavra blog. Fan pages de redes sociais não foram considerados como blogs.

2. Os blogs pré-selecionados tiveram suas páginas visitadas para verificar se a temática do blog era mesmo a deficiência e se pelo menos um de seus autores é pessoa com deficiência. Não foram incluídos no estudo blogs de atualidades, policiais, de recrutamento, conhecimento geral, religiosos, de concursos, de economia, clínicos, de direito, dentre outras temáticas encontradas. Os blogs que possuíam a temática deficiência e cujos autores não eram pessoas com deficiência foram excluídos, pois meu intuito era mostrar como a mobilidade urbana é abordada nos blogs sob a óptica de pessoas com deficiência. Foram excluídos também os blogs sem mecanismo de busca interno de suas matérias, pois isso inviabiliza a recuperação de postagens sobre mobilidade urbana do conteúdo dos blogs.

3. Em seguida, foi realizada a busca de postagens nos blogs selecionados utilizando como palavras-chave o termo "mobilidade urbana". Em cada blog selecionado, após a quantificação do número de resultados e da identificação do período das postagens, foi selecionada para análise a postagem mais recente entre aquelas publicadas entre fevereiro de 2012 e outubro de 2014 (uma vez que a lei $12.587 / 2012$ entrou em vigor em janeiro de 2012) e que atendesse aos seguintes critérios: possuir mais de dez linhas e abordar a temática mobilidade urbana, mesmo que ela não fosse o assunto predominante do texto. Em cada um dos blogs selecionados, caso a postagem mais recente não atendesse a estes critérios, era substituída pela segunda postagem mais recente que atendesse aos 
critérios de inclusão. Os blogs em que nenhuma das postagens atendeu aos critérios de inclusão foram excluídos do estudo. As postagens foram coletadas entre os dias 26 e 28 de outubro de 2014.

Todas as postagens coletadas foram lidas e analisadas com o emprego da Grounded Theory (Teoria Fundamentada nos Dados), conforme Strauss (1987) e Tarozzi (2011). 0 foco de análise realizada com o emprego da Grounded Theory não é meramente coletar ou ordenar uma massa de dados, mas organizar ideias emergentes da análise de dados (Strauss, 1987). Os resultados dessa análise foram dispostos no diagrama expresso na Figura 1.

Para compor a base teórico-discursiva deste artigo, foram selecionados 5 artigos a partir de buscas realizadas, no período de outubro a novembro de 2014, nas bases de dados SciElo e Google Acadêmico com o emprego dos seguintes termos em português ou inglês: mobilidade urbana, conceito de mobilidade urbana, acessibilidade e mobilidade urbana para pessoas com deficiência, urban mobility, urban mobility and disability e urban mobility sustainable. Foram utilizados também uma tese de doutorado, documentos legais (a Constituição da República Federativa do Brasil, a Lei 12.587/2012, o Decreto 7.612/2011 e a Convenção sobre os Direitos das Pessoas com Deficiência), uma publicação da OCDE (Organização para Cooperação e Desenvolvimento Econômico), duas publicações do governo brasileiro e dois livros.

Para facilitar o encadeamento do texto, o tópico "Resultados e Discussão" foi dividido em quatro partes: "Características gerais dos blogs", "Necessidade de mudança na estrutura das cidades", "Efetivação das mudanças na mobilidade urbana e a inclusão de pessoas com deficiência" e "Políticas públicas e programas relacionados à mobilidade urbana sustentável para as pessoas com deficiência no Brasil". A primeira parte do

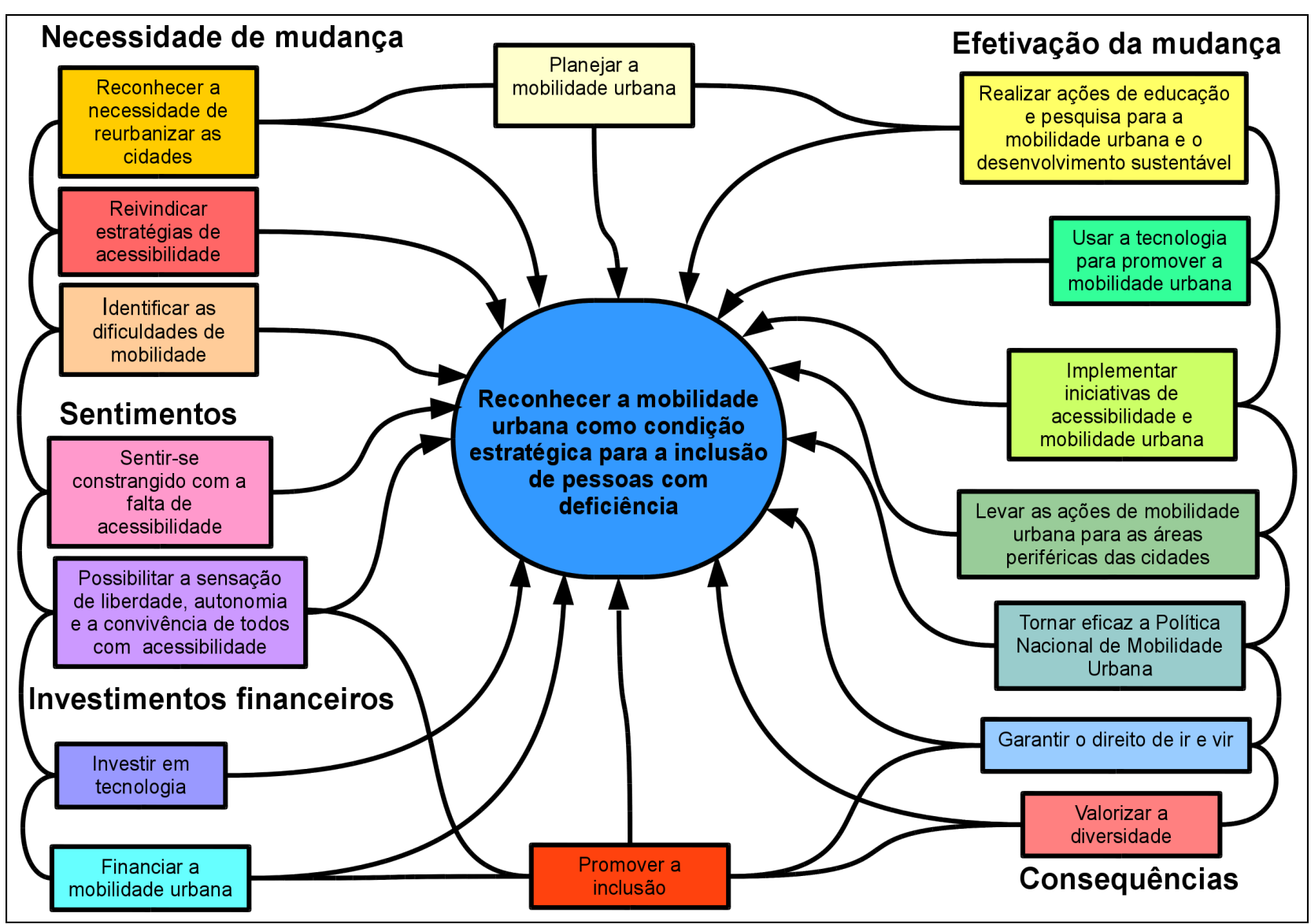

Figura 1 - Diagrama dos eixos, categoria central e subcategorias emergentes da análise das postagens de blogs de pessoas com deficiência à luz da Grounded Theory

Fonte: Elaborado pela pesquisadora com base nos dados deste estudo. 
tópico "Resultados e Discussão”, "Características gerais dos blogs", tem como finalidade apenas apresentar o cenário do qual as postagens foram retiradas e, como a análise dos dados foi qualitativa, não há nesta parte pretensão de realizar nenhuma inferência estatística. As demais partes do tópico "Resultados e Discussão" têm como finalidade apresentar e discutir os resultados da análise qualitativa, a qual apontou que, apesar de transcorridos três anos da publicação da Lei 12.587/2012, as pessoas com deficiência ainda anseiam por melhorias na acessibilidade e condições inclusivas de mobilidade urbana das cidades brasileiras.

\section{Resultados e discussão}

\section{Características gerais dos blogs}

Os blogs selecionados pelo estudo são em sua maioria de pessoas da região Sudeste do Brasil (11 blogs), mas 3 são da região Sul e apenas 1 é da região Nordeste. As regiões Norte e Centro-Oeste não foram representadas. De acordo com informação colhida nos blogs, 8 deles pertencem a cadeirantes, 3 a cegos, 1 a pessoa com dificuldade motora, 1 a pessoa amputada, 1 a pessoa com sequela de poliomielite e 1 a um grupo de pessoas com deficiência ( 2 cadeirantes, 1 cega, 1 surda e 1 com deficiência física não especificada).

Os blogs possuem média de 9,47 postagens com o uso do termo "mobilidade urbana", considerando o número de resultados obtidos na busca realizada em cada blog com o uso do termo supracitado. As postagens selecionadas para análise foram publicadas entre julho de 2012 e outubro de 2014, com predomínio daquelas publicadas no ano de 2014 (11). Dez blogs indicaram a utilização de fontes para a elaboração de suas postagens, sendo outros websites a fonte mais utilizada (6 dos blogs utilizaram este tipo de fonte); o que significa que, para elaborar e/ou fundamentar seus textos, a maioria dos autores das postagens analisadas realizam pesquisas na internet e divulgam a fonte que utilizaram, indicando que eles se preocupam com a qualidade e/ou confiabilidade das informações que publicam em seus blogs. Dez postagens foram redigidas como notícia/divulgação, 4 como texto de opinião e 1 como entrevista. A mobilidade urbana e/ou a acessibilidade foi a temática predominante de 7 das postagens dos blogs analisados. Algumas postagens possuíam outras temáticas relacionadas à mobilidade urbana e à acessibilidade como temáticas principais, mas abordavam estas temáticas em maior ou menor grau e, por isso, foram consideradas.

\section{Necessidade de mudança na estrutura das cidades}

0 estudo das postagens demonstrou que os blogs não são apenas diários virtuais da vida real que expressam os sentimentos, as vivências e divulgam os assuntos de interesse das pessoas com deficiência. São espaços de compartilhamento em que estas pessoas tentam ajudar umas às outras a resolver problemas relacionados à deficiência, trocam e buscam informações; além de ser também espaços de reivindicação, discussão, reflexão, crítica, mobilização e politização das pessoas com deficiência.

Da análise qualitativa, elaborada com base na Grounded Theory, emergiu como categoria central "Reconhecer a mobilidade urbana como condição estratégica para a inclusão de pessoas com deficiência" e dezesseis subcategorias, organizadas em cinco eixos concatenados entre si e com a categoria central - necessidade de mudança, efetivação da mudança, sentimentos, investimentos financeiros e consequências (Figura 1).

Do primeiro eixo da análise, intitulado "Necessidade de mudança", emergiram as seguintes subcategorias inter-relacionadas, a saber: "identificar as dificuldades de mobilidade", "reivindicar estratégias de acessibilidade" e "reconhecer a necessidade de reurbanizar as cidades". É importante ressaltar que esse reconhecimento deve ser de todos, inclusive da sociedade e de todas as esferas governamentais e não apenas das pessoas com deficiência e suas famílias. Todas as subcategorias do eixo Necessidade de mudança concatenam-se à subcategoria "sentir-se constrangido com a falta de acessibilidade" presente no eixo Sentimentos.

Dentre as unidades de sentido reunidas na subcategoria "identificar as dificuldades de mobilidade", citamos as mais representativas das dificuldades que as pessoas com deficiência encontram para se locomover nas cidades:

Dificuldades de mobilidade: ruas apertadas, calçadas cheias de obstáculos e que não comportam um cadeirante; transporte como barreira à locomoção; ausência de sinal sonoro dificulta mobilidade de pessoas com deficiência 
visual; problemas nas calçadas: calçada malconservada, com buracos, com entulho, inacabada, ou inexistência de calçada; falha na construção de rampas rebaixadas nas calçadas; rampas que são obstruídas por postes, buracos, que estão pela metade, ou ainda que não têm ligação com o outro lado da rua.

O trecho abaixo, extraído de uma das postagens analisadas por este estudo, corrobora a subcategoria "identificar as dificuldades de mobilidade" do eixo necessidade de mudança, bem como as unidades de sentido supracitadas:

Uma das coisas que mais me chama a atenção é a falha na construção de rampas rebaixadas nas calçadas. Já vi rampas que são obstruídas por postes, buracos, que estão pela metade, ou ainda que não têm ligação com o outro lado da rua. 0 cadeirante desce por uma rampa e do outro lado não há nenhuma. Eu sou um simples usuário comum das calçadas, não tenho conhecimento de engenharia, mas eu imagino que é necessário haver um estudo para fazer isso direito, não é mesmo? (Bonfim, 2012)

Estes problemas presentes no cotidiano das pessoas com deficiência têm se tornado cada vez maiores no decorrer dos anos; pois, de acordo com Teles (2007), a mobilidade urbana cresceu exponencialmente e complexificou-se pela imensa cadeia de necessidades de deslocamentos diários que se formou devido à dispersão urbanística residencial e à desnuclearização das atividades provenientes de novas formas de organização profissional e de novos estilos de vida, provocando o aumento das distâncias e o crescimento da necessidade de uso do automóvel, bem como ocasionando a desorganização do espaço público, a criação de barreiras urbanísticas que impedem o acesso de pessoas com deficiência à cidade e, consequentemente, a exclusão dessas pessoas, apesar das leis e normas de acessibilidade vigentes.

Nesta conjuntura, até recentemente, as questões de mobilidade urbana no Brasil têm se centrado em aspectos relacionados à prestação de serviços de transporte e na criação de uma infraestrutura de transportes por meio da ampliação de rodovias e vias expressas para a priorização do transporte individual em detrimento do transporte coletivo e dos modos não motorizados de locomoção, caracterizando uma completa desconexão entre os planejamentos urbano e de transportes. Portanto, embora os planos de ação de mobilidade urbana neste país sejam focados na disponibilidade de infraestrutura de transportes e serviços, baseando-se principalmente na construção de rodovias e na provisão insuficiente de transporte público, eles não costumam estar associados a um planejamento de transportes urbano e metropolitano compreensível e integrado (Silva \& Costa, 2008). Esse planejamento voltado para apenas um aspecto das necessidades de mobilidade urbana dos brasileiros tem se mostrado desconectado da realidade e incapaz de atender às demandas de toda a população, inclusive das pessoas com deficiência que, muitas vezes, possuem dificuldades até para sair de casa como expresso por muitas das postagens dos blogs que foram analisadas neste estudo.

A falta de um planejamento da mobilidade urbana que atenda às necessidades da população, principalmente no que concerne à qualidade e ao valor do transporte público, levou muitas pessoas às manifestações populares deflagradas no ano de 2013 no Brasil, fazendo com que a mobilidade urbana retornasse à agenda da sociedade e das políticas públicas, passando a ocupar espaço na mídia, mobilizando a opinião pública e chamando a atenção do governo (Gomide \& Galindo, 2013). Apesar de ter tido menos destaque na mídia, as pessoas com deficiência também foram às ruas e se mobilizaram para reivindicar seus direitos, dentre os quais o direito à mobilidade urbana e à acessibilidade. A necessidade de reivindicar este direito foi expressa neste estudo na subcategoria "reivindicar estratégias de acessibilidade", bem como no fato de que duas das postagens analisadas eram convocatórias para mobilizações de pessoas com deficiência, nas quais a mobilidade urbana encontrava-se na pauta.

Tanto o desencadeamento de reivindicações de melhorias na mobilidade urbana, expressa na subcategoria "reivindicar estratégias de acessibilidade", quanto a identificação das mudanças que precisam ser feitas, que emergiram por meio da subcategoria "identificar as dificuldades de mobilidade", conduzem à terceira subcategoria do eixo de necessidades de mudança, que é "reconhecer a necessidade de reurbanizar as cidades". Esta manifesta a necessidade de um bom planejamento urbano, de preparar as cidades para a diversidade da população, promovendo assim cidades acessíveis que propiciem a inclusão das pessoas com deficiência. 0 trecho da postagem abaixo evidencia as subcategorias supracitadas: 
[...] nós, pessoas com deficiência, familiares, amigos, entidades e demais atores da sociedade civil organizada, viemos a público solicitar aos membros dos poderes Executivo, Legislativo, Judiciário e instâncias de controle social, que nos ouçam e nos apoiem para continuar avançando e para que tenhamos, de fato, inclusão social à altura de nossos tempos. [...] Queremos ter acesso ao transporte público, calçadas transitáveis, semáforos com sinalização sonora, pisos táteis, enfim, estratégias de acessibilidade que nos assegurem o direito fundamental de ir e vir. Tudo isso precisa chegar à periferia, não dá para ficar apenas no discurso, ou pior, tornando acessível um ponto ou outro e criando uma ilusão de que a cidade está sendo pensada para todos. (Garcia, 2013)

A necessidade de elaboração e execução de um planejamento urbano eficaz e inclusivo foi expresso pelas postagens dos blogs por meio da subcategoria "Planejar a mobilidade urbana", a qual se encontra na interface entre os eixos necessidades de mudança e efetivação da mudança. 0 trecho de uma das postagens analisadas por este estudo evidencia esta necessidade, bem como demonstra a importância de melhor concatenação entre as leis vigentes e a efetivação do planejamento urbano:

A legislação é clara e tem que ser cumprida. Não podemos mais ficar nos desculpando por nossas cidades pouco acessíveis. É necessário planejar bem frente a desafios tão grandes e recursos limitados. Um bom caminho é aproveitar a Política Nacional de Mobilidade Urbana, que determina que municípios com mais de 20 mil habitantes elaborem e apresentem um Plano Municipal de Mobilidade Urbana, para planejar e priorizar as questões relativas à acessibilidade e inclusão da pessoa com deficiência. (Assis, 2014)

0 agravamento dos problemas de mobilidade urbana das cidades e a fragmentação dos seus sistemas de transportes têm estimulado a revisão dos conceitos empregados atualmente e o desenvolvimento de um novo paradigma de mobilidade urbana no Brasil (Silva \& Costa, 2008). Assim, embora a efetivação da inclusão das pessoas com deficiência demande uma série de mudanças na sociedade (envolvendo aspectos relacionados à saúde, à educação, ao combate ao preconceito e às condições de acesso ao emprego, à renda, ao lazer, dentre outros), a mobilidade urbana é considerada uma condição estratégica, pois a falta de condições adequadas de acessibilidade e mobilidade urbana restringe as pessoas com deficiência ao ambiente doméstico e/ou às instituições assistencialistas, reduzindo sua autonomia e possibilidade de independência e, consequentemente, dificultando sua convivência com as outras pessoas, bem como seu acesso à educação, saúde, cultura, emprego, dentre outros aspectos relacionados à dimensão social do desenvolvimento sustentável.

\section{Efetivação das mudanças na mobilidade} urbana e a inclusão de pessoas com deficiência

A exclusão social imposta pelas dificuldades de mobilidade urbana que as pessoas com deficiência enfrentam faz com que elas vivenciem sentimentos negativos como o preconceito, conforme indica a subcategoria "Sentir-se constrangido com a falta de acessibilidade" no eixo "Sentimentos" do diagrama (Figura 1). Esta subcategoria encontra-se evidenciada no fragmento abaixo extraído do Blog das Pessoas com Deficiência:

[...] o transporte ainda é uma grande barreira e nossas ruas e calçadas representam grande obstáculo para a locomoção de pessoas com deficiência, que também sofrem com a falta de acessibilidade em lojas e edifícios, sem contar o preconceito e o não cumprimento da legislação vigente, que ainda perduram. (Assis, 2014)

As dificuldades de mobilidade das pessoas com deficiência podem evocar sentimentos de inferioridade que promovem táticas de evasão e/ou comportamento que inibam sua mobilidade e movimentação, propiciando sua reclusão e, consequentemente, reforçando sua exclusão social. Portanto, a mobilidade urbana para pessoas com deficiência não é circunscrita apenas pelo designer do ambiente construído, mas também por atitudes e práticas socioculturais, o que significa que uma política de mobilidade urbana que contemple as pessoas com deficiência não pode estar dissociada de desafios mais amplos que envolvem a reformulação de valores hegemônicos e práticas sociais (Imrie, 2000).

A reformulação de práticas e valores humanos relacionados à deficiência e um redesenho inclusivo das cidades podem promover a consubstanciação 
da categoria central deste estudo, "Reconhecer a mobilidade urbana como condição estratégica para a inclusão de pessoas com deficiência", a qual se relaciona com a segunda subcategoria do eixo "Sentimentos": Possibilitar a sensação de liberdade, autonomia e a convivência de todos com acessibilidade. 0 trecho abaixo, retirado de uma das postagens analisadas, corrobora esta subcategoria:

Promover acessibilidade é permitir conhecer o outro. É permitir a convivência de todos com todos. [...] É preciso que as pessoas entendam que acessibilidade não é liberdade só para alguns, é para todos. No momento em que meus amigos que não precisam de ambientes acessíveis passam a cobrar acessibilidade dos estabelecimentos para que eu possa os acompanhar, a acessibilidade não é algo só para mim, é para todos que convivem comigo. (Rocha, 2014)

0 redesenho inclusivo das cidades compreende uma série de realizações, as quais emergiram neste estudo por meio das seguintes subcategorias, agrupadas no eixo efetivação da mudança: "Realizar ações de educação e pesquisa para a mobilidade urbana e o desenvolvimento sustentável", "Usar a tecnologia para promover a mobilidade urbana", "Implementar iniciativas de acessibilidade e mobilidade urbana", "Levar as ações de mobilidade urbana para as áreas periféricas das cidades" e "Tornar eficaz a Política Nacional de Mobilidade Urbana". Estas subcategorias encontram-se aparentes em muitos dos trechos das postagens supracitados. $\mathrm{O}$ fragmento abaixo evidencia o anseio das pessoas com deficiência por melhores tecnologias, o que reforça as subcategorias "Usar a tecnologia para promover a mobilidade urbana" e "Investir em tecnologia", bem como a importância de que este investimento seja feito de forma condizente com as necessidades destas pessoas:

[...] pesquisadores de grandes centros de pesquisa nacionais [...] apresentam protótipos e produtos que visem aprimorar a mobilidade das pessoas com deficiência no ambiente urbano. (Ricardo, 2014)

Não dá mais para aceitar o discurso de que não se tem porque é caro [...]. A ideia de que se deve disponibilizar não o melhor, mas o mais barato, tem feito o Estado brasileiro gastar fortunas com ajudas técnicas que pouco nos ajudam. (Garcia, 2013)
As subcategorias "Realizar ações de educação e pesquisa para a mobilidade urbana e o desenvolvimento sustentável" e "Usar a tecnologia para promover a mobilidade urbana" demonstram a necessidade de realização de mais pesquisas no âmbito brasileiro no intuito de criar novas estratégias e dispositivos tecnológicos ambientalmente responsáveis, planejados com base no desenho universal no intuito de facilitar a mobilidade urbana sustentável das pessoas com deficiência, o que contemplará todas as pessoas, pois uma cidade projetada sob a égide do desenho universal é acessível a todos, independentemente de suas limitações físicas e sensoriais permanentes ou temporárias e/ou necessidades circunstanciais como aquelas apresentadas por gestantes, crianças e pessoas com carrinho de bebê ou malas. Todavia, ações educativas podem possibilitar o uso inclusivo dos recursos de acessibilidade e evitar atitudes como a obstrução de rampas, passeios e vagas especiais pelo estacionamento de carros de pessoas sem deficiência.

Neste sentido, a educação para a mobilidade tem que ser melhorada, devendo ser realizada não apenas nas escolas primárias, mas também em outros níveis de ensino. Além disso, deve ser combinada também com a gestão da mobilidade para que as pessoas se habituem à mobilidade sustentável, pois esta deve envolver a participação do município como um todo (inclusive docentes, pais e discentes) e ser realizada nas escolas, nos ambientes domésticos e de convivibilidade social (OCDE, 2004).

De acordo com Camagni et al. (2002), na Europa, os governos têm incentivado a sustentabilidade urbana e a experimentação de políticas de planejamento inovadoras devido à convicção amplamente compartilhada de que os altos custos de infraestrutura e energia, o congestionamento das redes de transportes, o aumento da segregação e especialização do uso da terra e a degradação do meio ambiente são elementos que tendem a afastar as cidades do modelo de desenvolvimento sustentável e minar sua compacidade e diversidade.

\section{Políticas públicas e programas relacionados à mobilidade urbana sustentável para as pessoas com deficiência no Brasil}

O Brasil possui acentuadas diferenças econômicas, sociais e estruturais nos sistemas de mobilidade de seus municípios (Silva \& Costa, 2008). Portanto, o Plano Municipal de Mobilidade Urbana (que deve ser 
elaborado a partir da Política Nacional de Mobilidade Urbana) propõe-se a assumir características distintas para contemplar as necessidades e potencialidades do contexto social no qual se encontra, o que denota que a elaboração de políticas públicas para a sua implementação é um problema complexo e multidimensional que possui um vasto número de variáveis e deve envolver a participação de diferentes atores (inclusive daqueles que possuem deficiência) devido às particularidades dos municípios.

A necessidade de eficácia da Política de Mobilidade Urbana brasileira no intuito de contemplar as especificidades dos municípios e das pessoas com deficiência encontra-se patente na subcategoria "Tornar eficaz a Política Nacional de Mobilidade Urbana", a qual, para se tornar realidade, depende da efetivação das subcategorias "Implementar iniciativas de acessibilidade e mobilidade urbana" e "Levar as ações de mobilidade urbana para as áreas periféricas das cidades". Esta última relaciona-se ao fato de que as periferias das cidades, e não apenas as suas áreas centrais, devem ser acessíveis e permitir a mobilidade das pessoas com deficiência. Se as iniciativas de mobilidade urbana e acessibilidade continuarem restritas aos centros das cidades, elas nunca poderão ser consideradas como implementadas, pois as pessoas com deficiência continuarão a encontrar dificuldades para sair de suas casas, chegar aos seus locais de trabalho e conviver em sociedade, pois suas possibilidades de locomoção estarão restritas a uma pequena área da cidade. Estas subcategorias podem ser evidenciadas pelo seguinte trecho retirado do Blog Inclusão Diferente:

Governantes, empresários e a sociedade em geral precisam se dar conta de que as pessoas com deficiência são cidadãos, contribuintes, consumidores e clientes como qualquer um. Viajam, apreciam a gastronomia, o teatro, o cinema, a música e a dança como qualquer pessoa. [...] Todos os espaços precisam ser acessíveis. Isso é bem difícil de se ver por aqui. No Brasil, é raro encontrar um museu onde haja possibilidades de um deficiente visual tocar as peças para conhecê-las ou ter audiodescrição das obras expostas, além da falta de acessibilidade física já conhecida nos espaços culturais. (Affonso, 2014)
A subcategoria "Implementar iniciativas de acessibilidade e mobilidade urbana" possui dentre suas unidades de sentido: implementar facilidades de locomoção, eliminar barreiras, criar iniciativas de mobilidade, tornar o setor de serviços acessível, implementar e detalhar o modelo de Plano Municipal de Acessibilidade e promover ambientes inclusivos. Segundo Vital (2006), o Programa Brasileiro de Acessibilidade Urbana, lançado em 2003, pelo Ministério das Cidades, também visa que, ao se garantir a mobilidade urbana às pessoas com deficiência, se promova o acesso a prédios públicos, estabelecimentos comerciais ou de serviços e áreas de lazer.

Para as pessoas com deficiência, a Política Nacional de Mobilidade Urbana, além de tornar a mobilidade urbana um tema prioritário, oferece a oportunidade de observação de normas de acessibilidade universais que lhes permitam o direito de ir e vir, o qual se encontra expresso na subcategoria "Garantir o direito de ir e vir" do eixo Consequências do diagrama (Figura 1):

0 tema [mobilidade urbana] se tornou prioritário no país com a vigência da 'Política Nacional de Mobilidade Urbana', que traz como uma de suas diretrizes a acessibilidade universal e a observação de normas e diretrizes de acessibilidade nos projetos e programas que visem o aperfeiçoamento da infraestrutura urbana. (Ricardo, 2014)

A Lei 12.587/2012 (Brasil, 2012) estipula que todos os municípios que possuem mais de $20 \mathrm{mil}$ habitantes e que são obrigados por lei a elaborar seu plano diretor deverão elaborar também um Plano de Mobilidade Urbana. Este é o instrumento de efetivação da Política Nacional de Mobilidade Urbana, devendo, portanto, incorporar seus princípios e diretrizes, mas também ser integrado ao plano diretor municipal.

Além disso, embora não o manifeste explicitamente, ao afirmar que os municípios sem sistema de transporte público coletivo ou individual devem incentivar e promover a infraestrutura necessária para o transporte não motorizado, realizado a pé ou de bicicleta, a Lei 12.587/2012 (Brasil, 2012) dá margem à elaboração e à execução de um Plano de Mobilidade Municipal de acordo com as realidades locais, bem como estimula deslocamentos ecologicamente sustentáveis.

No que concerne à implementação da mobilidade urbana e da acessibilidade, a Lei $12.587 / 2012$ (Brasil, 2012) apresenta dentre seus objetivos a 
promoção do desenvolvimento sustentável com a mitigação dos custos socioeconômicos e ambientais do deslocamento de pessoas e cargas nas cidades e a melhoria das condições urbanas de acessibilidade e mobilidade da população. Dentre suas diretrizes, encontram-se o incentivo ao desenvolvimento técnico-científico e à utilização de energias renováveis e menos poluentes, contemplando, em vários de seus artigos, a previsão de atendimento das necessidades de mobilidade urbana das pessoas com deficiência, uma vez que menciona a equidade nos transportes públicos coletivos e nos espaços de circulação pública, a inclusão social e a acessibilidade, definindo esta última como facilidades que possibilitem a todos autonomia nos deslocamentos desejados, o que se coaduna com a subcategoria "Possibilitar a sensação de liberdade, autonomia e a convivência de todos com a acessibilidade" do eixo "Sentimentos".

A sensação de liberdade, autonomia e a possibilidade de convivência de todos como apregoa a Constituição de 1988 (Brasil, 1988) e como desejam as pessoas com deficiência depende de aspectos sociais, econômicos, ambientais e da conscientização de todas as pessoas para que se abandone o preconceito e se valorize a diversidade e as pessoas como elas são, promovendo assim uma efetiva inclusão, na qual as pessoas com deficiência tenham garantido o seu direito de ir e vir, não sejam julgadas por suas limitações e sim valorizadas por suas capacidades. Se a Política de Mobilidade Urbana brasileira for efetivada em sua totalidade, ela contribuirá para que essa mudança de paradigma em relação à deficiência se torne realidade, conforme expresso nas subcategorias "Garantir o direito de ir e vir", "Valorizar a diversidade" e "Promover a inclusão", as quais se efetivarão mais facilmente juntamente com a operacionalização pelos governos da categoria central "Reconhecer a mobilidade urbana como condição estratégica para a inclusão de pessoas com deficiência", a qual implica primeiramente a operacionalização das subcategorias do eixo Efetivação da mudança.

0 reconhecimento da mobilidade urbana como condição estratégica para a inclusão de pessoas com deficiência e sua efetivação em estratégias de promoção da inclusão dependem de investimentos em tecnologias e de financiamentos, conforme expresso nas subcategorias "Investir em tecnologia" e "Financiar a mobilidade urbana" do eixo Investimentos financeiros. A Lei 12.587/2012 (Brasil, 2012) estabelece que deve constar, de acordo com as possibilidades financeiras da União, dos Estados, do Distrito Federal e dos Municípios, em seus respectivos projetos de planos plurianuais e de leis de diretrizes orçamentárias, recursos financeiros para aprimorar os sistemas de mobilidade urbana e a qualidade de seus serviços. Além disso, os Planos de Mobilidade Urbana devem contemplar mecanismos e instrumentos de financiamento do transporte público coletivo e da infraestrutura de mobilidade urbana. Para tanto, os governos municipais poderão subsidiar o custeio da tarifa dos transportes públicos, o que não isenta seus beneficiários diretos e indiretos de contribuírem com o custeio destes serviços. Todavia, Gomide \& Galindo (2013) afirmam que as manifestações referentes à tarifa do transporte coletivo realizadas em 2013 e conhecidas como "Jornadas de Junho" deixaram patente a necessidade de novas fontes de financiamento que não sejam provenientes apenas das tarifas cobradas dos usuários e que toda a sociedade deveria contribuir com o custeio do transporte público coletivo. Entretanto, o investimento em mobilidade urbana não deve se resumir ao custeio do transporte público.

O Programa Brasileiro de Acessibilidade Urbana possui o objetivo de estimular e apoiar os governos municipais e estaduais a desenvolverem ações que promovam o acesso de pessoas com deficiência e mobilidade reduzida aos sistemas de transporte, equipamentos urbanos e circulação em áreas públicas por meio do estabelecimento de uma nova visão de construção das cidades que considere o acesso universal ao espaço público, contemplando as diferentes necessidades das pessoas para viver em sociedade. Para tanto, este programa propõe-se a lançar mão de alguns instrumentos, dentre os quais destacam-se a criação de novas fontes de financiamento, a implantação de bancos de dados, a realização de cursos e seminários nacionais e internacionais e a realização e o fomento a pesquisas (Vital, 2006).

O Plano Nacional dos Direitos da Pessoa com Deficiência - Viver sem Limite, lançado pelo Decreto 7.612/2011 (Brasil, 2011a, 2013) também visa estimular o desenvolvimento de tecnologias assistivas que facilitem o cotidiano das pessoas com deficiência, inclusive no que concerne à mobilidade, por meio da criação de centros tecnológicos para formar treinadores e instrutores de cães-guia, da instituição do Programa Nacional de Inovação em Tecnologia e da criação de linhas de crédito para que as pessoas com deficiência 
possam adquirir algumas das tecnologias assistivas de que necessitam, tais como cadeiras de rodas motorizadas e adaptações em veículos automotores.

Implementado pelo Ministério da Ciência e Tecnologia (MCTI) e pela Finep (Agência Brasileira da Inovação), o Programa Nacional de Inovação em Tecnologia Assistiva visa apoiar o desenvolvimento de inovações em produtos, metodologias, estratégias, práticas e serviços que aumentem a autonomia, o bem-estar e a qualidade de vida das pessoas com deficiência. Para tanto, a Finep propõe-se a fornecer recursos para que universidades, institutos de pesquisa ou empresas desenvolvam inovações de alto risco tecnológico associadas às oportunidades de mercado (Brasil, 2013).

Por fim, cabe notar que, embora existam leis e programas voltados à mobilidade urbana e à inclusão das pessoas com deficiência no Brasil, inclusive no que concerne à previsão de destinação orçamentária para obras de reurbanização das cidades e investimento em pesquisas e inovação em tecnologias assistivas, estes nem sempre são implementados e/ou têm sua implementação restrita a algumas cidades ou áreas urbanas. A mobilidade urbana não pode ser encarada como um privilégio de alguns e sim como direito de todos. Por isso, precisam ser implementadas ações promotoras de mobilidade urbana de maneira mais ampla e eficaz, capazes de atender a todos, independentemente de suas necessidades. Só assim o reconhecimento da mobilidade urbana como condição estratégica para a inclusão de pessoas com deficiência se consolidará na prática enquanto um dos aspectos-chave da efetiva promoção da inclusão das pessoas com deficiência na sociedade brasileira e não permanecerá apenas como anseio e reivindicação de pessoas que se deparam cotidianamente com as barreiras urbanas que dificultam ou impedem que elas exerçam seu direito de ir e vir e tenham uma vida socioeconômica ativa.

\section{Considerações finais}

As postagens analisadas demonstram que os blogs de pessoas com deficiência não se configuram como um mero passatempo. Ao contrário, são instrumentos bastante concatenados com o próprio cotidiano dessas pessoas e com a realidade que as cerca e que são empregados para evidenciar suas necessidades, reivindicações, reflexões, para discutir e apontar soluções para os problemas que enfrentam em seu cotidiano, bem como para expressar seus sentimentos em relação às situações que vivenciam.

Os blogs são, portanto, instrumentos de luta e articulação das pessoas com deficiência, evidenciando que elas não são um público passivo. Ao contrário, as pessoas com deficiência são um público bastante consciente de suas dificuldades e necessidades e que utiliza os blogs não apenas como diários da vida real, mas também como uma forma de articulação, mobilização, politização e geração de conhecimento.

Da análise qualitativa das postagens dos blogs realizada com base na Grounded Theory, emergiu como categoria central "Reconhecer a mobilidade urbana como condição estratégica para a inclusão de pessoas com deficiência", da qual derivaram dezesseis subcategorias organizadas em cinco eixos e inter-relacionadas entre si e com a categoria central. No primeiro eixo, intitulado "Necessidade de mudança", encontram-se três subcategorias: "Identificar as dificuldades de mobilidade", "Reivindicar estratégias de acessibilidade" e "Reconhecer a necessidade de reurbanizar as cidades". No segundo eixo, "Sentimentos", encontram-se duas subcategorias de cunho mais subjetivo, a saber: "Sentir-se constrangido com a falta de acessibilidade" e "Possibilitar a sensação de liberdade, autonomia e a convivência de todos com a acessibilidade". O terceiro eixo, "Efetivação da mudança", é composto por seis subcategorias ("Planejar a mobilidade urbana", "Realizar ações de educação e pesquisa para a mobilidade urbana e o desenvolvimento sustentável", "Usar a tecnologia para promover a mobilidade urbana", "Implementar iniciativas de acessibilidade e mobilidade urbana", "Levar as ações de mobilidade urbana para as áreas periféricas das cidades" e "Tornar eficaz a Política Nacional de Mobilidade Urbana") que, se efetivadas, podem atender às necessidades de mudanças expressas no primeiro eixo, bem como contribuir para a inclusão social das pessoas com deficiência, conforme expresso nas três subcategorias presentes no quinto eixo, intitulado Consequências: "Garantir o direito de ir e vir", "Valorizar a diversidade" e "Promover a inclusão". Todavia, para que isso se concretize também é necessária a efetivação do quarto eixo, "Investimentos financeiros", consubstanciado em 
suas duas subcategorias: "Investir em tecnologia" e "Financiar a mobilidade urbana".

Disso se depreende que as postagens demonstraram que a mobilidade urbana é considerada pelas pessoas com deficiência como uma condição estratégica para sua inclusão social; mas, para que esta se concretize, são necessárias mudanças por meio da identificação das dificuldades de mobilidade que enfrentam e da reivindicação de estratégias de acessibilidade que propiciarão o efetivo reconhecimento por todas as esferas do poder público da necessidade de reurbanizar as cidades. De acordo com o auferido nas postagens, essas mudanças poderão se efetivar por meio de uma série de ações de promoção da mobilidade urbana, as quais se iniciam pelo planejamento, que deve ser articulado com ações educativas, pesquisas e tecnologias capazes de promover e implementar a acessibilidade e a mobilidade urbana sustentável que contemple todas as pessoas, inclusive aquelas que possuem deficiência, o que implica o fato de que estas ações não podem se restringir às áreas centrais, mas devem ser implementadas também nas periferias das cidades.

A consecução dessas ações promoveria a eficácia da Política Nacional de Mobilidade Urbana, que é um dos anseios das pessoas com deficiência no Brasil; mas, para tanto, são necessários financiamentos e investimentos em tecnologia que favoreçam a efetivação dessa e de outras políticas, bem como de programas que ajudariam a garantir o direito de ir e vir das pessoas com deficiência e a promover a valorização da diversidade e, consequentemente, a tão almejada inclusão dessas pessoas, o que significa possibilitar que elas possam conviver em sociedade e ter uma vida ativa.

Assim, a análise dos dados evidenciou que, por meio de suas postagens, os blogs delineiam um panorama completo e articulado sobre a conjuntura da mobilidade urbana para pessoas com deficiência no Brasil, que precisa receber mais atenção do poder público no que concerne à execução das várias mudanças que as cidades necessitam para se tornarem efetivamente inclusivas e acessíveis para todos. Por fim, percebe-se que a análise supracitada demonstrou que as pessoas com deficiência reconhecem a importância da Política Nacional de Mobilidade Urbana, mas acham que ela não está sendo implementada como deveria no que concerne à efetivação do seu direito de ir e vir e anseiam que ela se torne eficaz.

\section{Referências}

Affonso, D. (2014). Pessoas com deficiência também precisam se divertir. Inclusão Diferente. Recuperado em 27 de outubro de 2014, de http://www.inclusaodiferente.net/2014/09/ pessoas-com-deficiencia-tambem-precisam.html

Assis, M. G. C. (2014). Novo secretário-adjunto da secretaria de estado dos direitos das pessoas com deficiência de São Paulo. 0 blog das pessoas com deficiência. Recuperado em 26 de outubro de 2014, de http://pessoacomdeficiencia. blogspot.com.br/2014/04/novo-secretario-adjunto-dasecretaria.html.

Bonfim, R. (2012). Site divulga fotos de calçadas malconservadas de Curitiba. Curitiba: Gazeta do Povo. Blog Inclusilhado. Recuperado em 27 de outubro de 2014 de http://www.gazetadopovo.com.br/blogs/inclusilhado/ site-divulga-fotos-de-calcadas-mal-conservadas-de-curitiba/.

Brasil. (1988, 05 de outubro). Constituição da República Federativa do Brasil de 1998. Brasília: Diário Oficial da União. Recuperado em 01 de fevereiro de 2012, de http://www. planalto.gov.br/ccivil_03/Constituicao/Constituicao.htm

Brasil. (2011a, 17 de novembro). Decreto $n^{\circ}$ 7.612, de 17 de novembro de 2011. Institui o Plano nacional dos direitos da pessoa com deficiência - plano viver sem limite. Brasília: Diário Oficial da União. Recuperado em 29 de novembro de 2011, de http://www.planalto.gov.br/ccivil_03/_Ato20112014/2011/Decreto/D7612.htm

Brasil. Secretaria de Direitos Humanos da Presidência da República - SDH. Secretaria Nacional de Promoção dos Direitos da Pessoa com Deficiência - SNPD. (2011b). Convenção sobre os Direitos das Pessoas com Deficiência: Protocolo Facultativo à Convenção sobre os Direitos das Pessoas com Deficiência: decreto legislativo n.o 186, de 09 de julho de 2008: decreto n. ${ }^{\circ}$ 6.949, de 25 de agosto de 2009 (4a. ed., rev. e atual.). Brasília: SDH/ SNPD.

Brasil. (2012, 03 de janeiro). Lei no 12.587, de 3 de janeiro de 2012. Institui as diretrizes da Política Nacional de Mobilidade Urbana; revoga dispositivos dos Decretos-Leis nos 3.326, de 3 de junho de 1941, e 5.405, de 13 de abril de 1943, da Consolidação das Leis do Trabalho (CLT), aprovada pelo Decreto-Lei no 5.452, de 10 de maio de 1943, e das Leis nos 5.917, de 10 de setembro de 1973, e 6.261, de 14 
de novembro de 1975; e dá outras providências. Brasília: Diário oficial da União. Recuperado em 20 de outubro de 2014, de http://www.planalto.gov.br/ccivil_03/_ato20112014/2012/lei/l12587.htm

Brasil. Secretaria de Direitos Humanos da Presidência da República - SDH. Secretaria Nacional de Promoção dos Direitos da Pessoa com Deficiência - SNPD. (2013). Viver sem limite - plano nacional dos direitos da pessoa com deficiência. Brasília: SDH/ SNPD.

Camagni, R., Gibelli, M. C., \& Rigamonti, P. (2002). Urban mobility and urban form: the social and environmental costs of different patterns of urban expansion. Ecological Economics, 40(2), 199-216. http://dx.doi.org/10.1016/ S0921-8009(01)00254-3

Cohen, R. (2006). Cidade, corpo e deficiência: percursos e discursos possíveis na experiência urbana (Tese de doutorado). Programa de Estudos Interdisciplinares de Comunidades e Ecologia Social, Universidade Federal do Rio de Janeiro, Rio de Janeiro.

Garcia, V. (2013). Manifesto paulista pelos direitos das pessoas com deficiência no dia 7/8 em SP. Deficiente Ciente. Recuperado em 26 de outubro de 2014, de http://www. deficienteciente.com.br/2013/08/manifesto-paulistapelos-direitos-das-pessoas-com-deficiencia-no-dia-070 8-em-sp.html

Gil, A. C. (2008). Métodos e técnicas de pesquisa social (6a. ed.). São Paulo: Atlas.

Gomide, A. Á., \& Galindo, E. P. (2013). A mobilidade urbana: uma agenda inconclusa ou o retorno daquilo que não foi. Estudos Avançados, 27(79), 27-39. http://dx.doi. org/10.1590/S0103-40142013000300003

Imrie, R. (2000). Disability and discourses of mobility and movement. Environment \& Planning, 32(9), 1641-1656. http://dx.doi.org/10.1068/a331

Magagnin, R. C., \& Silva, A. N. R. (2008). A percepção do especialista sobre o tema mobilidade urbana. Transportes, 16(1), 25-35. http://dx.doi.org/10.14295/transportes. v16i1.13
Minayo, M. C. S. (2007). 0 desafio da pesquisa social. In M. C. S. Minayo, S. F. Deslandes \& R. Gomes (Eds.). Pesquisa social: teoria, método e criatividade (26a. ed.). Petrópolis: Vozes.

Organização para Cooperação e Desenvolvimento Econômico - OCDE. (2004). Communicating environmentally sustainable transport. The role of soft measures. Paris: OCDE. Recuperado em 19 de outubro de 2014, de http://www.oecd-ilibrary. org/environment/communicating-environmentallysustainable-transport_9789264106642-en

Ricardo, L. (2014). 6o encontro de tecnologia para pessoas com deficiência e desfile de moda inclusiva. Blog do deficiente físico. Recuperado em 26 de outubro de 2014, de http:// www.deficientefisico.com/6o-encontro-de-tecnologia-parapessoas-com-deficiencia-e-desfile-de-moda-inclusiva/.

Rocha, B. (2014). Um dia as coisas serão diferentes... Porto Alegre: Esclerose múltipla e eu. 0 dia a dia de uma esclerosada. Recuperado em 27 de outubro de 2014, de http://esclerosemultiplaeeu.blogspot.com.br/2014/05/ um-dia-as-coisas-serao-diferentes.html.

Silva, A. N. R., \& Costa, M. S. (2008). Multiple views of sustainable urban mobility: the case of Brazil. Transport Policy, 15(6), 350-360. http://dx.doi.org/10.1016/j. tranpol.2008.12.003

Strauss, A. L. (1987). Qualitative analysis for social scientists. Cambridge: Cambridge University Press.

Tarozzi, M. (2011). O que éa Grounded Theory? Metodologia de pesquisa e de teoria fundamentada nos dados. Petrópolis: Vozes.

Teles, P. (2007). Desenhar cidades com mobilidade para todos - o caso prático da rede nacional de cidades e vilas com mobilidade para todos. Cadernos Sociedade e Trabalho, 8, 57-68.

Vital, F. M. P. (2006). Mobilidade urbana: fator de inclusão da pessoa com deficiência (Boletim Técnico da CET, No. 40). São Paulo: Companhia de Engenharia de Tráfego.

Recebido: Fev. 02, 2015

Aprovado: Maio 03, 2015 